\title{
PHARMACOKINETIC DRUG INTERACTION BETWEEN CLOPIDOGREL AND ESOMEPRAZOLE IN ADULT HEALTHY MALE VOLUNTEERS
}

\author{
BHARGAV K ${ }^{1}$, VENKATA SUBBAREDDY B ${ }^{1}$, VENKATA SIVAKRISHNA K ${ }^{1}$, HIMAJA G ${ }^{1}$, SAMUEL GIDEON GEORGE P $^{1 *}$, \\ BHASKAR REDDY $\mathrm{K}^{2}$
}

${ }^{1}$ Department of Pharmacy Practice, Sri Venkateshwara College of Pharmacy, Chittoor - 517 127, Andhra Pradesh, India. ${ }^{2}$ Department of Pharmaceutics, Sri Venkateshwara College of Pharmacy, Chittoor - 517 127, Andhra Pradesh, India.

Email: psgsamuel@gmail.com

Received: 02 April 2017, Revised and Accepted: 19 April 2017

\begin{abstract}
Objective: Proton pump inhibitors (PPIs) are known to impair cytochrome P2C19 mediated activation of clopidogrel, the antiplatelet agent used for cardiovascular risk prevention. Esomeprazole is an optical isomer of omeprazole with better efficacy and tolerability than conventional PPIs. Esomeprazole is often co-administered with clopidogrel considering the risk of associated gastrointestinal bleeding. This study was designed to determine the effect of esomeprazole on the mean pharmacokinetic profile clopidogrel.
\end{abstract}

Methods: A total of 14 adult healthy male participants who volunteered participation were enrolled, randomized equally into two cross-over sequences, dosed with clopidogrel and clopidogrel + esomeprazole in respective periods. Blood samples were collected through antecubital or forearm vein indwelling catheter. Concentration of clopidogrel parent prodrug in isolated plasma was determined using validated sensitive liquid chromatography - mass spectrometry. Pharmacokinetic modeling was carried out using PKSOLVER add-in for Microsoft Excel.

Results: The pharmacokinetic profile of clopidogrel was non-significantly altered by esomeprazole. Statistically significant difference in peak plasma concentration, apparent volume of distribution, and clearance of clopidogrel was observed only during period II in participants co-dosed with esomeprazole ( $\mathrm{p}=0.0483,0.0011$, and 0.0015 , respectively). All other primary and secondary pharmacokinetic parameters displayed minor alterations during either period ( $\mathrm{p}>0.05)$.

Conclusion: The non-significant alteration of clopidogrel pharmacokinetics by esomeprazole can be potentiated by underlying predisposing factors such as the presence of CYP2C19 allelic variants and increasing the risk of cardiovascular events. Hence, co-administration of clopidogrel and esomeprazole should be under clinical monitoring and is not recommended in poor responders of antiplatelet therapy with clopidogrel.

Keywords: Clopidogrel, CYP2C19, Esomeprazole, Enzyme inhibition, Pharmacokinetics.

(C) 2017 The Authors. Published by Innovare Academic Sciences Pvt Ltd. This is an open access article under the CC BY license (http://creativecommons. org/licenses/by/4. 0/) DOI: http://dx.doi.org/10.22159/ajpcr.2017.v10i7.18855

\section{INTRODUCTION}

Clopidogrel is a platelet adenosine diphosphate receptor antagonist indicated for the prophylaxis of atherosclerotic events including myocardial infarction, ischemic stroke and vascular death manifested either by recent stroke, or established peripheral vascular disease [1]. It is a prodrug that requires a two-step oxidative biotransformation process for conversion into an inactive and active metabolite of clopidogrel (AMC) involving human carboxylesterase 1 and CYP450 enzymes including CYP1A2, CYP2B6, CYP2C9, CYP2C19, and CYP3A4/5 [2,3]. Besides the implication of diverse CYP450 enzymes in clopidogrel activation, the role of CYP2C19 is prominent and well established [4]. Altered genetic patterns of CYP2C19 are associated with diminished platelet response to clopidogrel treatment and poor cardiovascular outcomes $[5,6]$. It has been reported that $4-30 \%$ of patients treated with clopidogrel do not display adequate therapeutic response, while about $10 \%$ of patients face unpleasant bleeding events [7]. Various drugs that are substrates or inhibitors of CYP2C19 tend to significantly alter clopidogrel pharmacokinetics precipitating impaired therapeutic response [8,9]. Proton pump inhibitors (PPI) are a class of potential antiulcer agents used for providing rapid symptom relief and healing in patients with peptic ulcer and gastroesophageal reflux disease [10]. PPIs are often prescribed with clopidogrel and low dose aspirin to prevent gastrointestinal (GI) bleeding and ulcers. Concomitant use of PPIs substantially decreases the risk of upper GI bleeding in patients receiving low-dose aspirin (LDA) and clopidogrel [11]. However, being inhibitors of the microsomal enzyme system, conventional PPIs such as omeprazole alter the mean pharmacokinetic profile of clopidogrel $[12,13]$. Coadministration of PPI and other CYP450 inhibitors with clopidogrel decreases AMC concentration with a parallel increase in the concentration of clopidogrel parent prodrug (CPP) magnifying the risk of cardiovascular events $[14,15]$. Esomeprazole is an optical isomer of omeprazole and is being broadly considered over other conventional PPIs owing to its high systemic bioavailability and prolonged duration of action [16]. In spite of retaining the CYP450 enzyme inhibition property of its parent racemic omeprazole, the standard $40 \mathrm{mg}$ dose of esomeprazole is being widely used due to a better pharmacodynamic response such as improved symptom resolution and mucosal healing $[17,18]$. This study was hence designed to study the effect of esomeprazole on the pharmacokinetic profile of clopidogrel. We considered CPP profiling over AMC owing to its chemical instability and low circulating levels which make quantification in plasma intricate [19].

\section{METHODS}

\section{Study site and approval}

This study was conducted for a period of 2 months in a tertiary care hospital. The protocol was reviewed and approved by the Institutional Ethics Committee before study commencement (Ref No.: IEC/RVSIMS/2017/04). Consent from the hospital authorities was obtained before using the clinical facilities and subject enrolment. 
Subject recruitment and confidentiality

Adult healthy male volunteers who were willing to participate were screened for factors that restrict their enrolment. All participants underwent a screening procedure comprising demographics, personal history, medical history, and clinical laboratory investigations before enrolment. The study protocol was explained to volunteer in his native language under the supervision of a registered medical practitioner. Participants were enrolled into the study only on provision of written informed consent. All data were documented in specially designed case report forms, and access was restricted to the investigator to ensure non-violation of subject rights and confidentiality.

\section{Sample size}

A total of 14 participants who met the inclusion criterion were enrolled into the study.

\section{Study sequences and design}

This randomized control study of $2 \times 2$ crossover design had two sequences on either period as shown in Table 1.

\section{Inclusion criterion}

- Healthy human male participants in the age sequence between 18 and 55 years and body mass index (BMI) within the range of $18.5-25 \mathrm{~kg} / \mathrm{m}^{2}$ with body weight not $<50 \mathrm{~kg}$

- Participants with no evidence of underlying disease during screening and medical history

- Participants whose screening laboratory values are within normal limits

- Participants should not have consumed any medication or furanocoumarin-containing fruit products $72 \mathrm{hrs}$ before dosing and throughout the study periods.

\section{Exclusion criterion}

- Participants with history of smoking, alcohol dependence, and alcohol abuse within the past 1 year

- Participants with history of abuse with amphetamines, cocaine, tetra hydro cannabinoids, benzodiazepines, barbiturates, and opioids within 1 year

- Participants with allergy or significant history of hypersensitivity or idiosyncratic reactions to clopidogrel or esomeprazole

- Participants with systolic blood pressure (BP) $<100$ and $>130 \mathrm{mmHg}$, diastolic pressure $<60$ and $>80 \mathrm{mmHg}$ and pulse rate $<60$ and $>100$ beats/min during screening

- Participants with history of dysphagia or difficulty in coming for follow-up

- Participants who had suffered any clinically significant illness within 1 month before study commencement

- Participants diagnosed with ulceration or history of gastric and/or duodenal ulcer during screening.

\section{Sampling method}

Blood samples were obtained from antecubital vein or forearm vein using an indwelling catheter. Heparin lock technique was used to prevent clotting of the indwelling catheter. After every blood sample collection, $0.5 \mathrm{ml}$ of heparinized saline was injected into the intravenous cannula to prevent clot formation. $5 \mathrm{ml}$ of blood sample was collected $1 \mathrm{hr}$ before dosing. $5 \mathrm{ml}$ of post-dose blood samples were collected at

Table 1: Study sequences and $2 \times 2$ crossover design

\begin{tabular}{lll}
\hline $\begin{array}{l}\text { Simple crossover } \\
\text { design }\end{array}$ & $\begin{array}{l}\text { Clopidogrel } \\
\text { (number of } \\
\text { participants) }\end{array}$ & $\begin{array}{l}\text { Esomeprazole + Clopidogrel } \\
\text { (number of participants) }\end{array}$ \\
\hline Period 1 & $7^{\mathrm{a}}$ & $7^{\mathrm{b}}$ \\
Period 2 & $7^{\mathrm{b}}$ & $7^{\mathrm{a}}$ \\
\hline
\end{tabular}

aParticipants dosed with clopidogrel in period I and both esomeprazole and clopidogrel in period II after a washout period of 15 days (Sequence I)

bParticipants dosed with both esomeprazole and clopidogrel in period I and clopidogrel in period II after a washout period of 15 days (Sequence II) the following time points (hours): $0.17,0.33,0.5,0.67,1.0,1.5,2.0,3.0$, 6.0, 8.0, and 12.0. Mean \pm standard deviation (SD) loss of blood from each volunteer during the entire study was $130 \pm 5 \mathrm{ml}$. Blood samples were collected in pre-labeled serum separator vacutainers, containing tri potassium ethylenediaminetetraacetic acid as an anticoagulant.

\section{Serum isolation and storage}

Blood samples were centrifuged at $4000 \mathrm{rpm}$ for 10 minutes at a mean \pm SD temperature of $4 \pm 2^{\circ} \mathrm{C}$ within 45 minutes of blood collection. The resulting plasma sample was separated into two aliquots and stored in pre-labeled Eppendorf tubes at $-70^{\circ} \mathrm{C}$ until analysis.

\section{Estimation of plasma clopidogrel concentrations}

CPP in human plasma was determined using sensitive liquid chromatography - mass spectrometry (LC-MS) technique. Clopidogrel bisulfate and ticlopidine obtained as gift samples were used as working and internal standard, respectively. Thermo TSQ Quantum Ultra LC-MS system was used for determination. ZORBAX Eclipse Plus C18 column of $4.6 \mathrm{~mm} \times 150 \mathrm{~mm}$ dimension and $5 \mu \mathrm{m}$ diameter was employed. 80:20\% v/v acetonitrile: $10 \mathrm{mM}$ ammonium acetate, respectively, was used as mobile phase. The column flow rate was $1 \mathrm{ml} / \mathrm{min}$ and injection volume of $10.0 \mu \mathrm{L}$. Protein precipitation technique was employed for extraction of the drug before loading into LC-MS. Four replicates of three different level quality control samples (high, medium, and low) were analyzed with each batch of subject samples.

\section{Pharmacokinetic modeling}

Peak plasma concentration $\left(\mathrm{C}_{\max }\right)$ and time taken to attain $\mathrm{C}_{\max }\left(\mathrm{t}_{\max }\right)$ were determined by visual inspection. Other pharmacokinetic parameters including $\mathrm{t}_{1 / 2}$, volume of distribution $\left(\mathrm{V}_{\mathrm{d}}\right)$, clearance $(\mathrm{Cl})$, area under the curve $\left(\mathrm{AUC}_{(0-\mathrm{t})}\right), \mathrm{AUC}_{(0-\infty)}$, area under mean curve (AUMC), and mean residence time (MRT) were calculated using PKSOLVER add-in for Microsoft Excel 2010. Pharmacokinetic parameters were based on the plasma concentration time using extravascular one-compartmental model.

\section{Statistical analysis}

Statistical analyses were performed using International Business Machines - Statistical Package for the Social Sciences (IBM - SPSS) 20.0. Statistical significance of difference in population means between and within participants was assessed by independent two-sample and paired samples t-test, respectively. Descriptive summary statistics are presented either as mean $\pm \mathrm{SD}$ or as median (minimum and maximum). Choice of descriptive and inferential statistical method was based on distribution normality as determined through normal probability plot.

\section{RESULTS}

\section{Demographics and clinical parameters}

A total of 19 healthy male volunteers who expressed willingness to participate underwent screening. Five volunteers who did not meet the inclusion criterion were restricted participation. Age wise distribution of 14 participants enrolled into the study is shown in Table 2. The subject dropout rate was $0 \%$ as all participants turned for period II after a washout period and no subject withdrew before completion of the study during either period.

The mean $\pm S D$ age of the participants was $33 \pm 5.53$ years with an age range of 24-44 years. All participants displayed normal BMI with a mean $\pm S D$ value of $22.4 \pm 1.1 \mathrm{~kg} / \mathrm{m}^{2}$. Subject safety was monitored through clinical laboratory evaluations during screening and postintervention, vital sign measurements during pre-intervention and at pre-determined time points post-intervention. Significant difference was not observed between daily BP $(p=0.471)$ and capillary blood glucose $(p=0.092)$. However, statistically significant mean reduction was observed with red blood cells (RBC), hemoglobin, hematocrit and white blood cells (WBC), and platelets. In addition, statistically significant increase in serum creatinine was observed as shown in Table 3 . 
Bioanalytical parameters

The mean \pm SD retention times of clopidogrel and ticlopidine were approximately $1.59 \pm 0.5$ and $1.77 \pm 0.5$ minutes, respectively. The overall chromatography run time was 2.5 minutes. The total accuracy for the quality control samples of clopidogrel ranged from $97.13 \%$ to $101.59 \%$ with percentage coefficient of variation (\%CV) ranging from $10.34 \%$ to $14.10 \%$. The calibration curve for clopidogrel is shown in Fig. 1.

$y=0.0002523 x+0.1292$, correlation coefficient $\left(r^{2}\right)=0.9946$

Intra-subject variability - Effect of esomeprazole on the pharmacokinetics of CPP

The mean pharmacokinetic profile of CPP was not found to be altered significantly by esomeprazole co-administration. $\mathrm{C}_{\max }$ of CPP was increased on esomeprazole administration in either sequence. However, the difference was statistically significant only in Sequence I as shown in Figs. 2 and 3. Similar period effects of $\mathrm{V} / \mathrm{F}$ and $\mathrm{CL} / \mathrm{F}$ observed in Sequence I was not observed in Sequence II. Mean intra-subject and inter-subject variability data for clopidogrel expressed as the mean $\% \mathrm{CV}$ are also given in Tables 4 and 5.

Intra-subject variability for $\mathrm{AUC}_{(0-t)}, \mathrm{AUC}_{(0-\infty)}$, and $\mathrm{C}_{\max }$ is $35.3 \%$, $32.8 \%$, and $29.4 \%$, respectively. Intra-subject variability for secondary parameters including $\mathrm{t}_{\max }, \mathrm{K}_{\mathrm{e}}, \mathrm{t}_{1 / 2} \mathrm{k}_{\mathrm{a}}, \mathrm{V} / \mathrm{F}, \mathrm{CL} / \mathrm{F}, \mathrm{AUMC}$, and MRT is $14.9 \%$, $18.9 \%, 14.9 \%, 30 \%, 32.8 \%, 35.9 \%$, and $15.1 \%$, respectively.

\section{Inter-subject variability}

Difference in pharmacokinetics of CPP was not observed between participants as shown in Figs. 4 and 5. Significant sequence effects of $\mathrm{V} / \mathrm{F}$ and $\mathrm{CL} / \mathrm{F}$ were observed during period II $(\mathrm{p}=0.0087$ and 0.0097 , respectively). The $\% \mathrm{CV}$ of inter-subject variability for primary pharmacokinetic parameters including $\mathrm{AUC}_{(0-t)}, \mathrm{AUC}{ }_{(0-\infty)}$, and $\mathrm{C}_{\max }$ are $31.6 \%, 29.0 \%$, and $20.6 \%$, respectively. Inter-subject variability for

Table 2: Summary of demographics

\begin{tabular}{lllll}
\hline S.No. & Parameter & \multicolumn{2}{l}{ Frequency $(\mathbf{N}=\mathbf{1 4})$} & \multirow{2}{*}{ Mean \pm SD } \\
\cline { 3 - 4 } & & Range & N (\%) & \\
\hline 1. & Age (years) & $18-35$ & $8(57.1)$ & $29.2 \pm 3.3$ \\
& & $36-50$ & $6(42.9)$ & $29.2 \pm 3.3$ \\
2. & Height $(\mathrm{cm})$ & $150-170$ & $11(78.6)$ & $167.6 \pm 6.25$ \\
& & $171-190$ & $3(21.4)$ & $167.6 \pm 6.25$ \\
3. & Mass $(\mathrm{kg})$ & $50-65$ & $8(57.1)$ & $64.35 \pm 6.03$ \\
& & $66-80$ & $6(42.9)$ & $64.35 \pm 6.03$ \\
4. & BMI $\left(\mathrm{kg} / \mathrm{m}^{2}\right)$ & $18-25$ & $14(100)$ & $22.4 \pm 1.1$ \\
\hline
\end{tabular}

BMI: Body mass index secondary pharmacokinetic parameters including $\mathrm{t}_{\mathrm{max}}, \mathrm{K}_{\mathrm{el}}, \mathrm{t}_{1 / 2} \mathrm{k}, \mathrm{V} / \mathrm{F}$, $\mathrm{CL} / \mathrm{F}, \mathrm{AUMC}$, and MRT is $16.4 \%, 23.6 \%, 25.0 \%, 26.8 \%, 29.0 \%, 31.7 \%$, and $15.8 \%$, respectively.

\section{DISCUSSION}

Clopidogrel and LDA are often combined with PPIs considering the associated risk of GI ulceration and bleeding. Despite the wellestablished potential to interact with clopidogrel through major CYP2C19 inhibition, PPI's cannot be replaced with histamine receptor antagonists

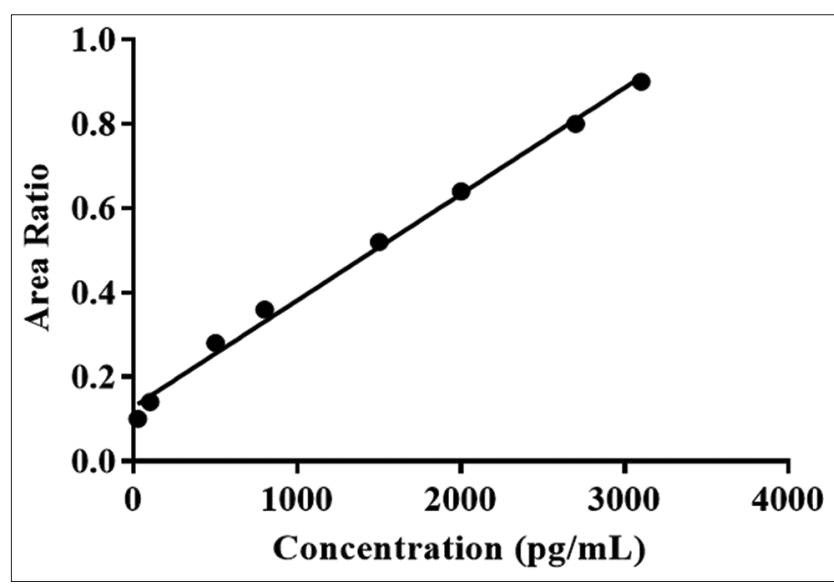

Fig. 1: Calibration curve for clopidogrel

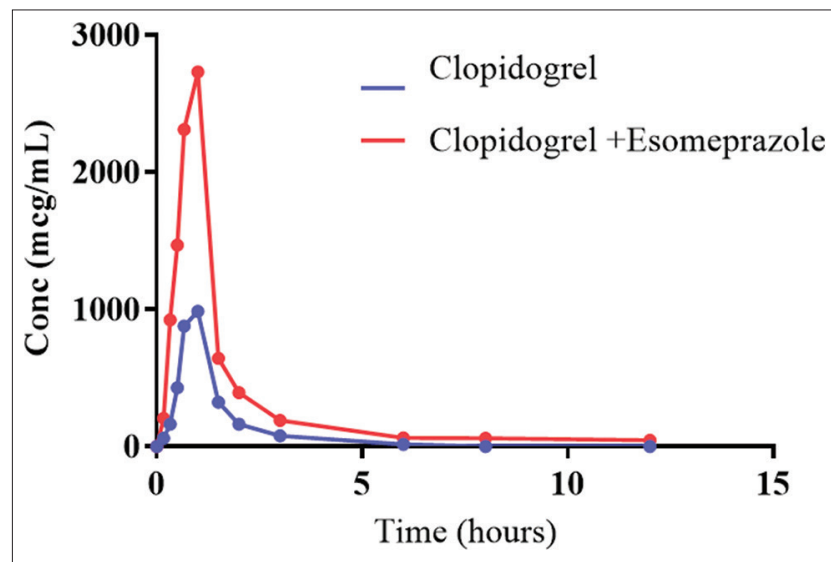

Fig. 2: Intra-subject variability observed in Sequence I

Table 3: Comparison of predosing and endpoint biochemical parameters

\begin{tabular}{|c|c|c|c|c|}
\hline S.No. & Biochemical parameter & Pre-intervention & Post-intervention & p values \\
\hline 1. & RBC (million $/ \mathrm{mm}^{3}$ ) & $5.04 \pm 0.42$ & $4.41 \pm 0.37$ & $<0.0001^{*}$ \\
\hline 2. & Hemoglobin (g/dL) & $13.65 \pm 1.06$ & $13.14 \pm 1.0$ & $0.0042^{*}$ \\
\hline 3. & Hematocrit $(\%)$ & $43.35 \pm 2.14$ & $38.21 \pm 2.08$ & $<0.0001^{*}$ \\
\hline 4. & Total WBC count (cells $/ \mathrm{mm}^{3}$ ) & $8385.7 \pm 2469.4$ & $6871.4 \pm 1572.7$ & $0.0146^{* *}$ \\
\hline 5. & Polymorphs (\%) & $58.07 \pm 5.22$ & $57.92 \pm 7.95$ & 0.9431 \\
\hline 6. & Lymphocytes (\%) & $32.07 \pm 6.04$ & $35.71 \pm 7.76$ & 0.0526 \\
\hline 7. & Eosinophils (\%) & $4.85 \pm 2.89$ & $4.14 \pm 1.12$ & 0.3889 \\
\hline 9. & Random blood sugar (mg/dL) & $89.14 \pm 12.97$ & $95.57 \pm 10.21$ & 0.2579 \\
\hline 10. & Blood urea nitrogen $(\mathrm{mg} / \mathrm{dL})$ & $10 \pm 3.29$ & $7.57 \pm 2.45$ & 0.0702 \\
\hline 11. & Serum creatinine $(\mathrm{mg} / \mathrm{dL})$ & $0.77 \pm 0.11$ & $0.96 \pm 0.09$ & $0.0001^{*}$ \\
\hline 12. & Bilirubin-total (mg/dL) & $1.14 \pm 0.73$ & $0.9 \pm 0.50$ & $0.0447 * *$ \\
\hline 13. & Bilirubin - Direct (mg/dL) & $0.3 \pm 0.18$ & $0.26 \pm 0.08$ & 0.3356 \\
\hline 14. & Bilirubin - Indirect (mg/dL) & $0.83 \pm 0.57$ & $0.63 \pm 0.43$ & 0.0538 \\
\hline 15. & SGOT (U/L) & $39.21 \pm 55.20$ & $23 \pm 10.53$ & 0.3024 \\
\hline 16. & SGPT (U/L) & $37.35 \pm 43.04$ & $27.07 \pm 17.69$ & 0.3722 \\
\hline
\end{tabular}

${ }^{*} \mathrm{p}<0.01,{ }^{* *} \mathrm{p}<0.05, \mathrm{p}$ value obtained through paired Student's t-test. SGOT: Serum glutamic-oxaloacetic transaminase, SGPT: Serum glutamic-pyruvic transaminase, RBC: Red blood cell, WBC: White blood cell 
Table 4: Effect of esomeprazole on CPP pharmacokinetics in Sequence I participants

\begin{tabular}{|c|c|c|c|c|c|}
\hline \multirow[t]{2}{*}{ S.No. } & \multirow[t]{2}{*}{ PK parameter } & \multicolumn{2}{|l|}{$($ Mean $\pm S D)$} & \multirow[t]{2}{*}{$\% \mathrm{CV}$} & \multirow[t]{2}{*}{ p value } \\
\hline & & Period $1^{c}$ & Period $2^{\mathrm{EC}}$ & & \\
\hline 1. & $\mathrm{t}_{1 / 2} \mathrm{k}_{\mathrm{a}^{*}}$ & $0.51 \pm 0.03$ & $0.434 \pm 0.15$ & 15.0 & 0.6034 \\
\hline 3. & $\mathrm{CL} / \mathrm{F}$ & $0.06 \pm 0.01$ & $0.029 \pm 0.01$ & 35.2 & 0.0015 \\
\hline 4. & $\mathrm{t}_{\text {max }^{* *}}$ & $0.78(0.83,0.65)$ & $0.64(1.18,0.41)$ & 15.2 & 0.5358 \\
\hline 5. & $\mathrm{C}_{\max }^{\max }$ & $632.27 \pm 92.1$ & $1831.36 \pm 1186.4$ & 41.5 & 0.0483 \\
\hline 6. & $\mathrm{~K}_{\mathrm{el}}$ & $1.24 \pm 0.01$ & $1.52 \pm 0.01$ & 15.4 & 0.2278 \\
\hline 7. & $\mathrm{AUC}_{(0-\mathrm{t})}$ & $1188.29 \pm 249.5$ & $3461.74 \pm 2721.8$ & 39.6 & 0.0897 \\
\hline 8. & $\mathrm{AUC}_{(0-\infty)}^{(-t)}$ & $1329.141 \pm 200.0$ & $3520.644 \pm 2705.7$ & 35.2 & 0.1006 \\
\hline 9. & AUMC & $2067.691 \pm 377.1$ & $5310.446 \pm 4612.2$ & 28.7 & 0.149 \\
\hline 10. & MRT & $1.55 \pm 0.11$ & $1.417368 \pm 0.45$ & 15.2 & 0.5324 \\
\hline
\end{tabular}

*Expressed as harmonic mean with pseudo-standard deviation, ${ }^{* *}$ Expressed as median (minimum, maximum), p values in bold text represent statistically significant difference (obtained by paired samples t-test). C: Clopidogrel, EC: Esomeprazole+clopidogrel. V/F, CL/F: Volume of distribution and clearance are expressed as a function of bioavailability, AUC: Area under the curve, AUMC: Area under mean curve, MRT: Mean residence time

Table 5: Effect of esomeprazole on CPP pharmacokinetics in Sequence II participants

\begin{tabular}{|c|c|c|c|c|c|}
\hline \multirow[t]{2}{*}{ S.No. } & \multirow[t]{2}{*}{ PK parameter } & \multicolumn{2}{|l|}{ Mean \pm SD } & \multirow[t]{2}{*}{$\% \mathrm{CV}$} & \multirow[t]{2}{*}{ p value } \\
\hline & & Period $1^{\mathrm{EC}}$ & Period $2^{c}$ & & \\
\hline 1. & $\mathrm{t}_{1 / 2} \mathrm{k}_{\mathrm{a}^{*}}$ & $0.36 \pm 0.19$ & $0.54 \pm 0.03$ & 14.8 & 0.3048 \\
\hline 3. & $\mathrm{CL} / \mathrm{F}$ & $0.03 \pm 0.01$ & $0.05 \pm 0.01$ & 30.5 & 0.1424 \\
\hline 4. & $\mathrm{t}_{\max }$ & $0.79(1.40,0.50)$ & $0.78(0.90,0.76)$ & 14.7 & 0.854 \\
\hline 5. & $\mathrm{C}_{\max }^{\max }$ & $982.66 \pm 209.3$ & $702.43 \pm 154.9$ & 17.2 & 0.0736 \\
\hline 6. & $\mathrm{~K}_{\mathrm{el}}^{\max }$ & $0.94 \pm 0.01$ & $1.18 \pm 0.01$ & 22.3 & 0.2773 \\
\hline 7. & $\mathrm{AUC}_{(0-t)}$ & $2234.32 \pm 718.2$ & $1415.5 \pm 371.4$ & 31.0 & 0.0868 \\
\hline 8. & $\operatorname{AUC}_{(0-\infty)}^{(0-\tau)}$ & $2438.34 \pm 715.6$ & $1568.37 \pm 378.5$ & 30.5 & 0.888 \\
\hline 9. & AUMC & $5051.41 \pm 2730.0$ & $2586.6 \pm 703.9$ & 43.0 & 0.1127 \\
\hline 10. & MRT & $1.93 \pm 0.65$ & $1.63 \pm 0.10$ & 15.0 & 0.3536 \\
\hline
\end{tabular}

*Expressed as harmonic mean with pseudo-standard deviation, ${ }^{* *}$ expressed as median (minimum, maximum), $\mathrm{p}$ value in this table represent no statistically significant difference ( $p>0.05)$ represent statistically significant difference (obtained by paired samples t-test). C: Clopidogrel, EC: Esomeprazole+clopidogrel, AUC: Area under the curve, AUMC: Area under mean curve, MRT: Mean residence time, V/F, CL/F: Volume of distribution and clearance are expressed as a function of bioavailability

$\left(\mathrm{H}_{2} \mathrm{RA}\right)$ as they are associated with risk of mucosal erosion in patients receiving antiplatelet therapy [20]. Therefore, it is crucial to identify PPIs with optimal enzyme inhibition property and high potency to prevent GI events in patients receiving clopidogrel, as non-adherence to antiplatelet agents develops after experiencing GI bleeding potentiating the risk of ischemic events [21]. In addition, the risk of cardiovascular events is precipitated by factors that impair production of AMC from CPP. Concentrations of CPP and AMC are known to be altered by several patient specific variables including demographics, personal and medical history, organ function, and concomitant medication [22-24]. To avoid variability arising due to gender and considering the risk of comparatively higher predisposition to adverse drug reactions, women volunteers were not enrolled into the study $[25,26]$. Although CYP2C19 activity is equal in both men and women, other factors such as higher gastric $\mathrm{pH}$, gastric-bowel transit times, and altered $\mathrm{V}_{\mathrm{d}}$ in women can cause variability in pharmacokinetics [27]. Bioavailability of clopidogrel active metabolite has been reported to be less in patients with higher body weight contributing to suboptimal treatment response [28]. Hence, to dodge the bias arising due to body weight, only participants with normal BMI (18.5-24.9 $\left.\mathrm{kg} / \mathrm{m}^{2}\right)$ were enrolled into the study. Volunteers with any other demographic factor, personal, and medical history that may impair the results of the study were limited participation. Clinical laboratory investigations were carried out pre- and post-intervention to ensure subject safety. A gross decrease in hematological parameters including RBC, hemoglobin, WBC platelets was observed at the study end point. Although they did not manifest as adverse hematological reactions, the changes in parameters were statistically significant. However, diverse hematological adverse effects such as anemia, agranulocytosis, leukopenia, and thrombocytopenia have been reported in patients receiving clopidogrel or LDA [29]. AMC is extensively protein bound (94\%) and hence minor change in plasma concentration would exert considerable effects on inhibition

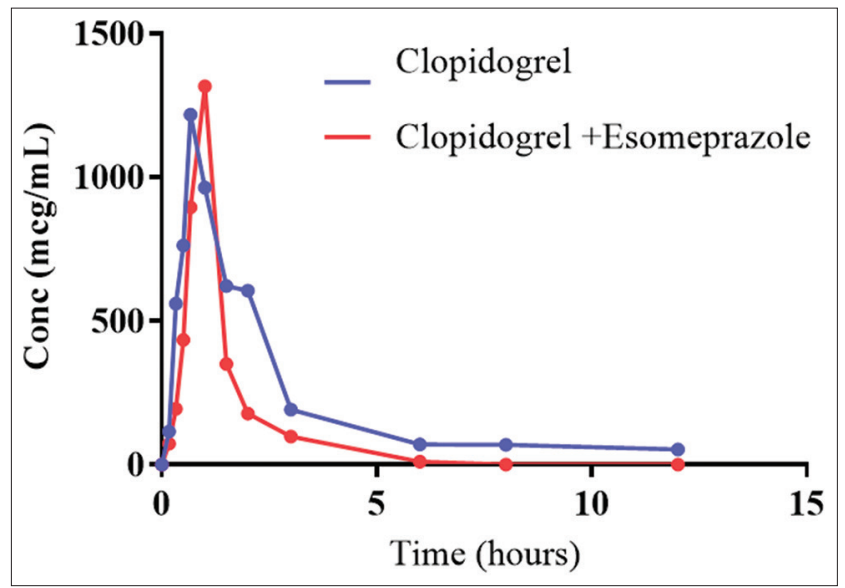

Fig. 3: Intra-subject variability in Sequence II

of platelet aggregation [30,31]. The pharmacologically active form of clopidogrel is clopidogrel thiol or AMC. Clopidogrel thiol is chemically unstable and has low circulating levels which make its determination in any biological matrix problematic [15]. Hence, we quantified CPP since a decrease in AMC is often accompanied by a parallel increase in CPP. Thus, considering the possible inverse relationship between CPP and AMC, CPP profiling was used as an indirect measure of AMC pharmacokinetics.

PPIs are well known to alter the pharmacokinetics of clopidogrel by impairing prodrug activation. We herein report insignificant alteration of CPP pharmacokinetics by esomeprazole. Although insignificant, 


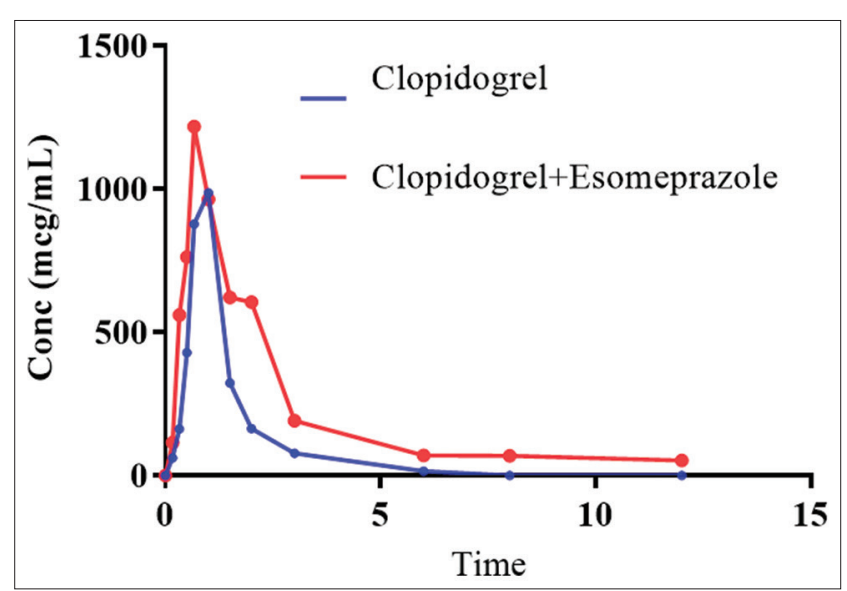

Fig. 4: Inter-subject variability in period I

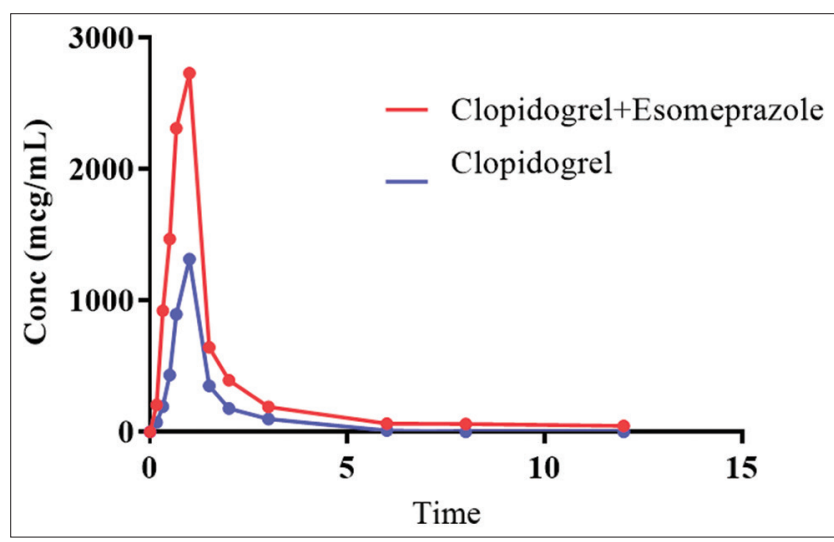

Fig. 5: Inter-subject variability in period II

variations in both primary and secondary parameters were observed during intra- and inter-subject variability analysis. $\mathrm{C}_{\max }$ of CPP was found to be increased by esomeprazole in both the sequences with a statistically significant increase in period II $\left(\Delta \mathrm{C}_{\text {max }}=1199.09 \mathrm{pg} / \mathrm{ml}\right.$, $\mathrm{p}=0.0483$ ). A transient increase in exposure to CPP with insignificant change in mean pharmacokinetic profile was observed on esomeprazole co-administration. Thus, systemic availability of AMC decreases and hence the exposure enhancing cardiovascular risks [32,33]. Significant alterations in clopidogrel $\mathrm{V} / \mathrm{F}$ and $\mathrm{CL} / \mathrm{F}$ observed in period II were not considered for further interpretation as such a difference was very negligible in period I. Hence change in clopidogrel V/F and CL/F could not be solely attributed to esomeprazole.

The magnitude of the studied interaction tends to be minor from our observations. Pharmacodynamic response to clopidogrel is largely affected by factors that decrease its bioavailability such as food, antacids and those that impair AMC production such as CYP450 allelic variations and enzyme inhibitors [34-37]. Although observed to be minor, severity of the interaction may be enhanced in patients with these underlying factors which decrease exposure to AMC. Hence, despite insignificant changes in pharmacokinetic profile, use of esomeprazole is not recommended in patients who are poor responders to clopidogrel so as to ensure adequate inhibition of platelet receptor activity.

\section{CONCLUSION}

The pharmacokinetic profile of CPP was found to be insignificantly altered by co-administration of esomeprazole. Minor changes in pharmacokinetic parameters observed could, however, be potentiated in the presence of underlying risk factors. Hence, concomitant administration of clopidogrel and esomeprazole should be under keen clinical supervision and is not recommended in poor responders to antiplatelet therapy with clopidogrel. The principal limitation of this study is that CPP concentrations were used as an indirect measure of AMC pharmacokinetics due to practical difficulties in AMC quantification. In spite of being previously reported, the reliability of such an assumption is often questionable as AMC concentrations may not merely have inverse relationships with that of CPP. Hence, further studies are necessary to study this interaction with direct AMC profiling with pharmacodynamic response monitoring.

\section{ACKNOWLEDGMENTS}

The generous contribution and guidance of Dr. Lakshmi $\mathrm{K}$ in interpretation of bio-analytical data are highly acknowledged. The authors are thankful to the management of Sri Venkateswara College of Pharmacy and RVS Institute of Medical Sciences, Chittoor, for the excellent research support and facilities rendered.

\section{REFERENCES}

1. Florian K, Hae YS, Volker K. Antiplatelet drugs in cardiological practice: Established strategies and new developments. Vasc Health Risk Manag 2008;4(3):637-45.

2. Katrin S, Teri EK, Russ BA. Clopidogrel pathway. Pharmacogn Genomics 2010;20(7):463-5.

3. Thomas M, John O. Metabolic activation of clopidogrel: In vitro data provide conflicting evidence for the contributions of CYP2C19 and PON1. Ther Adv Drug Saf 2011;2(6):253-61.

4. Caitrin WM, Leslie AM, Braxton DM, Yan GP, Richard BH, Joshua PL, et al. CYP2C19 metabolizer status and clopidogrel efficacy in the secondary prevention of small subcortical strokes (SPS3) study. J Am Heart Assoc 2015;4(6):e001652.

5. Pare G, Mehta SR, Yusuf S, Anand SS, Connolly SJ, Hirsh J, et al. Effects of CYP2C19 genotype on outcomes of clopidogrel treatment. N Engl J Med 2010;363(18):1704-14.

6. Johnson JA, Roden DM, Lesko LJ, Ashley E, Klein TE, Shuldiner AR. Clopidogrel: A case for indication-specific pharmacogenetics. Clin Pharmacol Ther 2012;91(5):774-6.

7. Nguyen TA, Diodati JG, Pharand C. Resistance to clopidogrel: A review of the evidence. J Am Coll Cardiol 2005;45(8):1157-64.

8. Zhi YW, Meng C, Ling LZ, LuShan Y, Su Z, Mei X, et al. Pharmacokinetic drug interactions with clopidogrel: Updated review and risk management in combination therapy. Ther Clin Risk Manag 2015;11:449-67.

9. Bates ER, Lau WC, Angiolillo DJ. Clopidogrel-drug interactions. J Am Coll Cardiol 2011;57(11):1251-63.

10. Carmelo S, Luigi G, Angelo Z, Corrado B. Effective and safe proton pump inhibitor therapy in acid-related diseases - A position paper addressing benefits and potential harms of acid suppression. BMC Med 2016;14:179-214.

11. Hiroshi Y, Yasumasa M, Yoshinori S, Sunichiro O, Shinya I, Masaki Y, et al. Treatment and prevention of gastrointestinal bleeding in patients receiving antiplatelet therapy. World J Crit Care Med 2015;4(1):40-6.

12. Meyer UA. Interaction of proton pump inhibitors with cytochromes P450: Consequences for drug interactions. Yale $J$ Biol Med 1996;69(3):203-9

13. Suresh DM, Hiren RT, Dinesh MP, Prashant SD, Chacko J. Impact of proton pump inhibitors on efficacy of clopidogrel: Review of evidence. Indian J Pharmacol 2011;43(2):183-6.

14. Shah BS, Parmar SA, Mahajan S, Mehta AA. An insight into the interaction between clopidogrel and proton pump inhibitors. Curr Drug Metab 2012;13(2):225-35.

15. Lau WC, Gurbel PA. The drug-drug interaction between proton pump inhibitors and clopidogrel. CMAJ 2009;180(7):699-700.

16. Gralnek IM, Dulai GS, Fennerty MB, Spiegel BM. Esomeprazole versus other proton pump inhibitors in erosive esophagitis: A metaanalysis of randomized clinical trials. Clin Gastroenterol Hepatol 2006;4(12):1452-8.

17. Li XQ, Andersson TB, Ahlstrom M, Weidolf L. Comparison of inhibitory effects of the proton pump-inhibiting drugs omeprazole, esomeprazole, lansoprazole, pantoprazole, and rabeprazole on human cytochrome P450 activities. Drug Metab Dispos 2004;32(8):821-7.

18. Kahrilas PJ, Falk GW, Johnson DA, Schmitt C, Collins DW, Whipple J, et al. Esomeprazole improves healing and symptom resolution as compared with omeprazole in reflux oesophagitis patients: A randomized controlled trial. The Esomeprazole Study Investigators. 
Aliment Pharmacol Ther 2000;14(10):1249-58

19. Karazniewicz-Lada M, Danielak D, Burchardt P, Kruszyna L, Komosa A, Lesiak M, et al. Clinical pharmacokinetics of clopidogrel and its metabolites in patients with cardiovascular diseases. Clin Pharmacokinet 2014;53(2):155-64.

20. Mo C, Sun G, Wang YZ, Lu ML, Yang YS. PPI versus histamine H2 receptor antagonists for prevention of upper gastrointestinal injury associated with low-dose aspirin: Systematic review and meta-analysis. PLoS One 2015;10(7):e0131558.

21. Cohen M. Expanding the recognition and assessment of bleeding events associated with antiplatelet therapy in primary care. Mayo Clin Proc 2009;84(2):149-60.

22. Gurbel PA, Bliden KP, Logan DK, Kereiakes DJ, Lasseter KC, White A, et al. The influence of smoking status on the pharmacokinetics and pharmacodynamics of clopidogrel and prasugrel: The PARADOX study. J Am Coll Cardiol 2013;62(6):505-12.

23. Deray G, Bagnis C, Brouard R, Necciari J, Leenhardt AF, Raymond F, et al. Clopidogrel activities in patients with renal function impairment. Clin Drug Investig 1998;16(4):319-28

24. Small DS, Farid NA, Li YG, Ernest CS $2^{\text {nd }}$, Payne CD, Salazar DE, et al. Effect of ranitidine on the pharmacokinetics and pharmacodynamics of prasugrel and clopidogrel. Curr Med Res Opin 2008;24(8):2251-7.

25. Beierle I, Meibohm B, Derendorf $\mathrm{H}$. Gender differences in pharmacokinetics and pharmacodynamics. Int J Clin Pharmacol Ther 1999;37(11):529-47

26. Rademaker M. Do women have more adverse drug reactions? Am J Clin Dermatol 2001;2(6):349-51.

27. Rubinow DR, Moore M. Sex-dependent modulation of treatment response. Dialogues Clin Neurosci 2004;6(1):39-51.

28. Wagner H, Angiolillo DJ, Ten Berg JM, Bergmeijer TO, Jakubowski JA, Small DS, et al. Higher body weight patients on clopidogrel maintenance therapy have lower active metabolite concentrations, lower levels of platelet inhibition, and higher rates of poor responders than low body weight patients. J Thromb Thrombolysis 2014;38(2):127-36.

29. Balamuthusamy S, Arora R. Hematologic adverse effects of clopidogrel. Am J Ther 2007;14(1):106-12.

30. Ganesan S, Williams C, Maslen CL, Cherala G. Clopidogrel variability: Role of plasma protein binding alterations. Br J Clin Pharmacol 2013;75(6):1468-77.

31. Venkateswaramurthy N, Krishnaveni K, Mercy FR, Sambath KR. Assessment of potential drug-drug interaction in stroke patients. Int J Pharm Pharm Sci 2016;8(12):221-4.

32. Jian JZ, Shao LC, Jie T, Ling L, Ying YZ, Hai MX. Increased risk for developing major adverse cardiovascular events in stented Chinese patients treated with dual antiplatelet therapy after concomitant use of the proton pump inhibitor. PLoS One 2014;9(1):e84985.

33. Mukesh K, Vicky D, Shruti M, Dinesh S, Neha M, Mangla R. Cardiovascular disease prevalence and drug utilization patterns at a tertiary care hospital in North Eastern India. Int J Pharm Pharm Sci 2016;8(6):116-9.

34. Nirogi RV, Kandikere VN, Mudigonda K. Effect of food on bioavailability of a single oral dose of clopidogrel in healthy male subjects. Arzneimittelforschung 2006;56(11):735-9.

35. McEwen J, Strauch G, Perles P, Pritchard G, Moreland TE, Necciari J, et al. Clopidogrel bioavailability: Absence of influence of food or antacids. Semin Thromb Hemost 1999;25 Suppl 2:47-50.

36. Shuldiner AR, O'Connell JR, Bliden KP, Gandhi A, Ryan K, Horenstein RB, et al. Association of cytochrome P450 2C19 genotype with the antiplatelet effect and clinical efficacy of clopidogrel therapy. JAMA 2009;302(8):849-57.

37. Hulot JS, Collet JP, Silvain J, Pena A, Bellemain-Appaix A, Barthélémy $\mathrm{O}$, et al. Cardiovascular risk in clopidogrel-treated patients according to cytochrome $\mathrm{P} 4502 \mathrm{C} 19 * 2$ loss-of-function allele or proton pump inhibitor coadministration: A systematic meta-analysis. J Am Coll Cardiol 2010;56(2):134-43. 